\title{
A Dual-Channel Enhanced Power Generation Architecture with Back-to-back Converter for MEA Application
}

\author{
Xiaoyu Lang \\ The University of Nottingham \\ Power Electronics, Machines and \\ Control Group (PEMC) \\ Nottingham, UK \\ Xiaoyu.Lang@nottingham.ac.uk \\ Chen $\mathrm{Li}$ \\ The University of Nottingham \\ Power Electronics, Machines and \\ Control Group (PEMC) \\ Nottingham, UK \\ eexc120@exmail.nottingham.ac.uk
}

\author{
Tao Yang \\ The University of Nottingham \\ Power Electronics, Machines and \\ Control Group (PEMC) \\ Nottingham, UK \\ Tao.Yang@nottingham.ac.uk \\ Serhiy Bozhko \\ The University of Nottingham \\ Power Electronics, Machines and \\ Control Group (PEMC) \\ Nottingham, UK \\ serhiy.bozhko@nottingham.ac.uk
}

\author{
Hossein Balaghi Enalou \\ The University of Nottingham \\ Power Electronics, Machines and \\ Control Group (PEMC) \\ Nottingham, UK \\ eexhb3@exmail.nottingham.ac.uk \\ Patrick Wheeler \\ The University of Nottingham \\ Power Electronics, Machines and \\ Control Group (PEMC) \\ Nottingham, UK \\ pat.wheeler@nottingham.ac.uk
}

\begin{abstract}
This paper presents a new electricity power generation architecture for the engine system of more electric aircraft (MEA). A starter/generator (SG) is connected to highpressure (HP) spool, and a generator is attached to low-pressure (LP) spool. Their outputs supply a common DC bus. A back-toback (B2B) converter is connected between the AC sides of two generators. There are two main contributions of the proposed idea. First, some power can be transferred from LP shaft to HP shaft via the B2B converter, which will benefit to reduce the fuel consumption and increase compressor surge margin of the engine. Second, the HP starter/generator could operate in a high speed without flux weakening, hence the magnitude of stator current will largely decrease when output same active power, leading to the reduction of overall power losses. Modeling and control method design are illustrated. The effectiveness of proposed power generation architecture, engine performance improvement and power loss reduction are verified.
\end{abstract}

Keywords- power transfer, more electric aircraft, power generation control, engine operating mode, starter/generator control.

\section{INTRODUCTION}

Recent years great progress has been made towards MEA due to advantages like gas emission reduction, decreased fuel consumption and etc. [1]. Due to increased electrical equipment on the MEA, the engine system is required to produce more electricity power. Conventionally, only a generator is linked to HP spool. However, extracting power only from HP spool will undermine the engine performance. In [2]-[3], it proved that there is a limit on the amount of power off-take from HP spool, otherwise the surge of compressor will happen. This can be addressed by bypassing excess air to fan discharge duct, whereas this will lead to fuel waste.
An alternative way is to use LP spool as an additional power source [4]-[7]. For example, in [4], a SG is attached to HP spool and a generator to LP spool. In [6], a SG, a generator and an electrical energy storage device are adopted to provide power to avionics, actuators and etc. Although those studies accomplish to extract power from both shafts, there are still some issues need to be studied. First, when engine operates at flight idle mode, like taxiing and descent, the speed of HighPressure Compressor (HPC) decreases which means HPC accepts less airflow. Thereby the bleeding is implemented between Low-Pressure Compressor (LPC) and HPC to bypass excess air to fan discharge duct, preventing the risk of LPC surge. However, this action creates the waste of thrust. Second, normally the operation speed of HP shaft is over $20000 \mathrm{r} / \mathrm{min}$ [1]. When adopting permanent magnet machine (PMM) as HP SG, large flux weakening current must be injected into HP SG to diminish the air gap flux density without outputting any active power. This will lead to great copper losses.

In this paper, a power generation architecture containing a B2B converter is proposed as shown in Fig. 1 to address those challenges. There are two main contributions: (1) Some power of LP shaft can be transferred to HP shaft via B2B converter by controlling HP SG in motoring mode to speed up the HP shaft. This will improve fuel efficiency and increase compressor surge margin; (2) HP SG could operate in a high speed without $\mathrm{FW}$. Hence, the magnitude of stator current will greatly decrease, reducing the overall copper losses.

This paper is organized as follows. Section II illustrates the modelling, design and control method of the system. In Section III, the effectiveness of proposed architecture and other characteristics are verified through simulations. Section IV makes a conclusion.
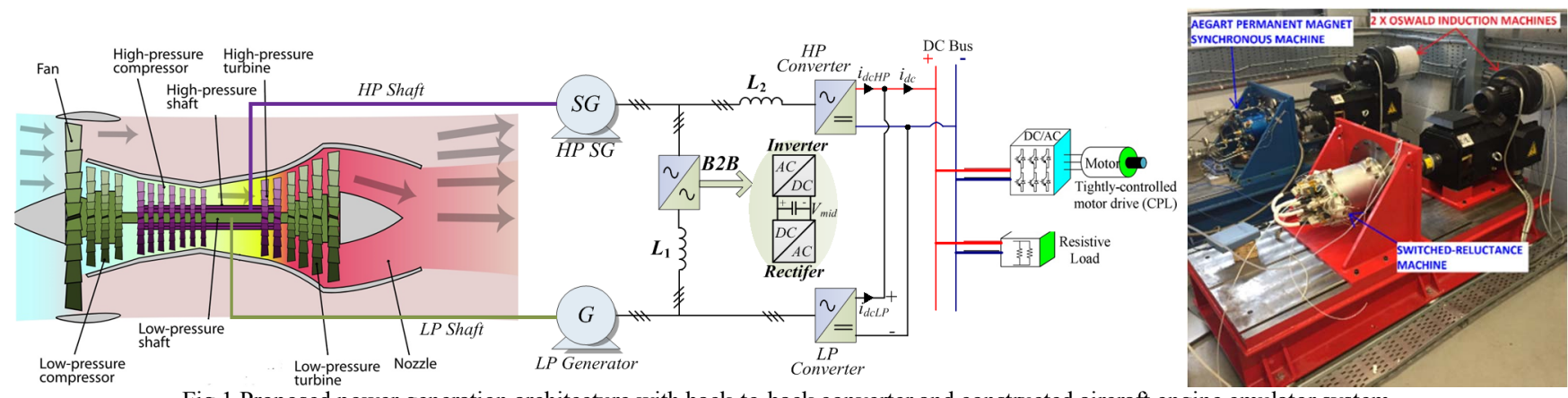

Fig.1 Proposed power generation architecture with back-to-back converter and constructed aircraft engine emulator system. 


\section{Modelling AND Control Method Design of PROPOSED SYSTEM}

Since LP generator generally outputs more power than HP SG [4], the B2B converter mainly serves to transfer power from LP to HP side. The intermediate voltage $V_{\text {mid }}$ is set as a high value since it doesn't supply loads directly. The power converters in Fig.1 can be classified according to their positions: LP Converter and Rectifier are LP side Converters; HP Converter and Inverter belong to HP side Converters. The inductors $L_{1}$ and $L_{2}$ serve to separate voltage sources. In this section, the modelling, control design of LP side power converters and selection of $L_{1}$ are illustrated. Those for HP side converters are conducted in the similar manner and won't be articulated due to limited space.

\section{A. Voltage Control for LP Converter}

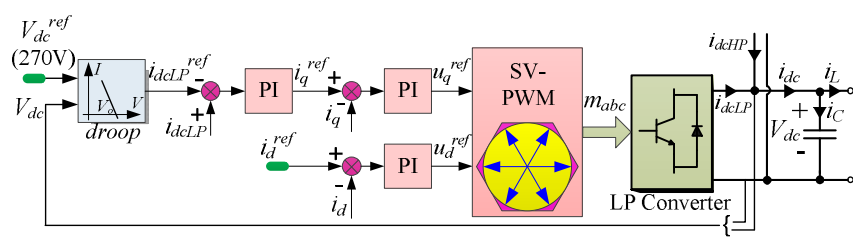

Fig.2 The control block diagram of LP power generation channel.

The control diagram of LP Converter is shown in Fig.2. Here the current-mode droop method in [8] is adopted to fulfil power sharing between LP and HP converters. The DC current reference is given as below, where $g_{L P}$ is the droop gain:

$$
i_{d c}{ }^{r e f}=\left(V_{d c}^{r e f}-V_{d c}\right) / g_{L P}
$$

The dynamic equations for PMM in generator mode in $d q$ frame are given as follow [15]:

$$
\left\{\begin{array}{l}
\frac{d i_{d}}{d t}=\frac{1}{L_{d}}\left(-u_{d}-R i_{d}+\omega_{e} L_{q} i_{q}\right) \\
\frac{d i_{q}}{d t}=\frac{1}{L_{q}}\left(-u_{q}-R i_{q}-\omega_{e} L_{d} i_{d}+\omega_{e} \psi_{f}\right)
\end{array}\right.
$$

where $u d, u q$ : $d q$-axes stator voltages; $i d, i q$ : $d q$-axes stator currents; $L_{d}, L_{q}: d q$-axes stator inductance; $R$ : stator resistance; $\psi_{f}$ : flux linkage of permanent magnet; $\omega_{e}$ : electrical rotor speed. For the surface-mounted PMM used in this paper, $L_{d}=$ $L_{q}=L_{s}$.

Since LP generator is connected to low pressure engine spool which has large moment of inertia, the mechanical constant can be treated as much slower than electrical constant. Then the linearized $q$ axis voltage can be derived:

$$
\Delta u_{q}=-\left(R+L_{s} s\right) \Delta i_{q}-\omega_{e} L_{s} \Delta i_{d}
$$

The linearized active power of the LP converter can be expressed as follows at operating point (indicated with "o"):

$$
\Delta P_{L P}=1.5\left(\Delta u_{d} i_{d s o}+u_{d o} \Delta i_{d s}+\Delta u_{q} i_{q s o}+u_{q o} \Delta i_{q s}\right)
$$

where $i_{d s o}$ and $i_{q s o}$ are obtained from LP side main branch currents $i_{a L s}, i_{b L s}$ and $i_{c L s}$ in Fig. 3 ; $P_{L P}$ : output power of LP Converter.

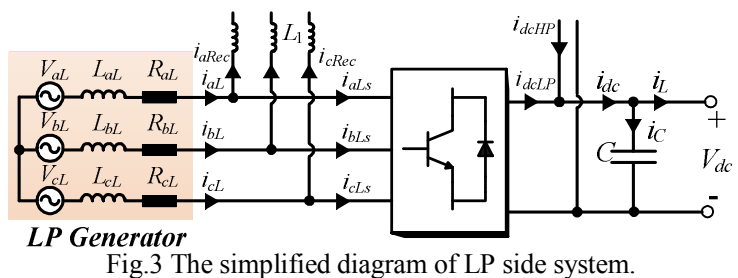

Assume the power ratio between LP generator and the power transferred to Rectifier is $n: 1$, then $i_{q}: i_{q s}=n:(n-1)$. Consider the situation that LP generator operates with $i_{d}=0$, the linearized active power of LP converter in small signal manner can be written as:

$$
\Delta P_{L P} \cong 1.5\left(\Delta u_{q} i_{q s o}+u_{q o} \Delta i_{q s}\right)=1.5\left[\rho u_{q o}-\left(R+L_{s} s\right) i_{q s o}\right] \Delta i_{q}
$$

where $\rho=(n-1): n$. Since the active power can also be represented as $\Delta P_{L P}=V_{d c} \Delta i_{d c L P}$, the transfer function between $\Delta i_{d c L P}$ and $\Delta i_{q}$ is:

$$
\frac{\Delta i_{d c L P}}{\Delta i_{q}}=\frac{1.5\left[\rho u_{q o}-\left(R+L_{s} s\right) i_{q s o}\right]}{V_{d c}}
$$

Considering $i_{d c}=P / V_{d c}$, the following relationship in small signal manner can be derived:

$$
\begin{aligned}
& C \frac{d \Delta V_{d c}}{d t}=\Delta i_{d c}-\Delta i_{L}=\left(\frac{\Delta P}{V_{d c o}}-\frac{P_{o}}{V_{d c o}{ }^{2}} \Delta V_{d c}\right)-\Delta i_{L} \\
& \Rightarrow \Delta V_{d c}=\frac{1}{C s+P_{o} / V_{d c o}{ }^{2}}\left(\Delta i_{d c}-\Delta i_{L}\right)
\end{aligned}
$$

Assume the power sharing ratio between LP Converter and HP Converter is $k: 1$, then the ratio of corresponding droop gains is $1: k$. Then the following relationship can be obtained:

$$
i_{d c L P}=k i_{d c H P} \Rightarrow i_{d c}=(1+1 / k) i_{d c L P}=\sigma i_{d c L P}
$$

Using equations (6)-(8), the control block diagram of LP Converter can be obtained in Fig.4. It is worth to note that in the generation mode, the active power flow is towards the DC link, this is the reason why the symbol for $\Delta i_{d c L P} r e f$ is negative.

Using the zero of voltage loop PI controller to eliminate the pole of forward path, the expression of PI controller can be given:

$$
\frac{k_{v p} s+k_{v i}}{s}=\frac{\omega_{c}\left(C s+P_{o} / V_{d c}^{2}\right)}{s}
$$

where $k_{v p}$ and $k_{v i}$ are the proportion and integration gains of PI controller, $\omega_{c}$ is a factor related to closed-loop bandwidth. (9) reveals that $k_{v p}$ and $k_{v i}$ are actually adaptive according to different operation conditions, like $P_{o}$ and $V_{d c}$. By tuning factor $\omega_{c}$ instead of $k_{v p}$ and $k_{v i}$, desirable transient and steady performance of DC voltage loop can be obtained.

The parameters of system are: $R_{s}=0.02 \Omega, L_{s}=99 \mu \mathrm{H}$, $V_{d c o}=270 \mathrm{~V}, C=1.5 \mathrm{mF}, \psi_{f}=0.036 \mathrm{~Wb}, 6$ poles. The desired closed voltage loop bandwidth is chosen as $200 \mathrm{~Hz}$. The closed voltage loop bode diagram is shown as Fig.5(a) when total output power varies from $20 \mathrm{~kW}$ to $60 \mathrm{~kW}$. In the lowfrequency region the magnitude is smaller than 0 . This can

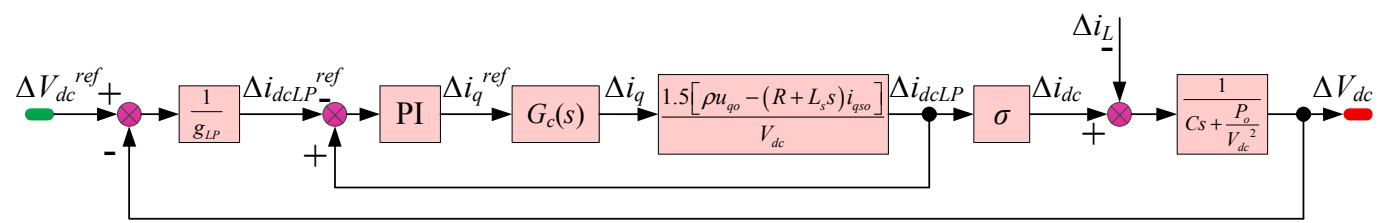

Fig.4 Control block diagram in small signal manner of voltage loop. 


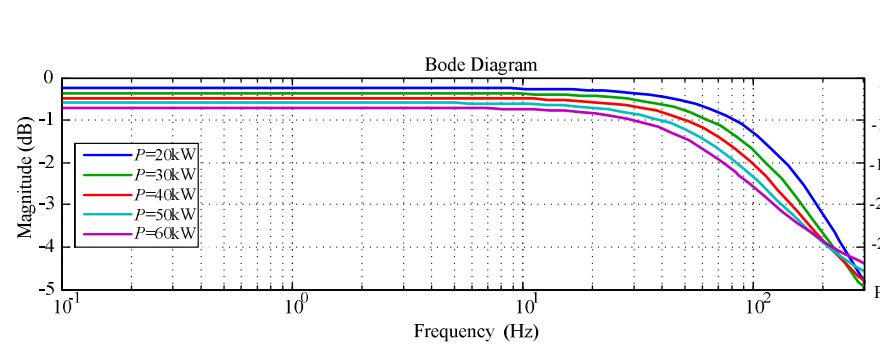

(a)

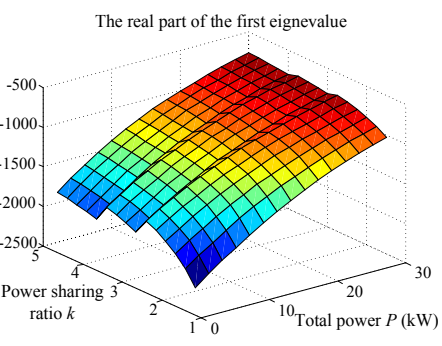

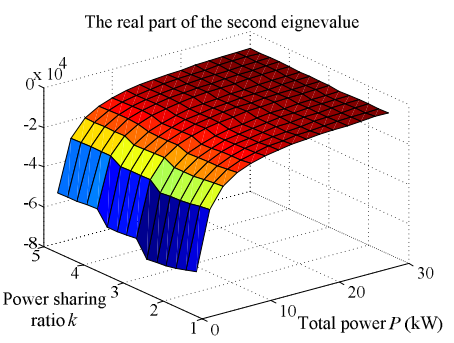

(b)

Fig.5 (a) Bode diagram of closed voltage loop; (b) Real parts of eigenvalues of closed voltage loop as the variation of power sharing ratio $k$ and total power $P$.

be explained by the droop effect: the actual DC voltage is smaller than the reference in load condition due to the droop characteristic. Moreover, at around $200 \mathrm{~Hz}$ the magnitude damps $-3 \mathrm{~dB}$ compared with the starting value in low frequency region. This proves the bandwidth of designed voltage loop is set to around $200 \mathrm{~Hz}$ by appropriately choosing the factor $\omega_{c}$.

The stability of voltage loop under different scenarios is also studied. The real parts of the closed loop eigenvalues are shown as the variation of power sharing ratio $k$ and total power $P$, as shown in Fig.5(b). It can be seen that even the power sharing ratio varies from 1.5 to 5 and total power varies from $1 \mathrm{~kW}$ to $30 \mathrm{~kW}$, all eigenvalues are always located at the left half plane of $s$ domain, therefore, the voltage control structure in Fig. 2 can not only offer a desired closed loop bandwidth, but also guarantee the overall stability.

\section{B. Selection of Inductor $L_{1}$}

The relationship of voltage vectors of LP side is given in Fig.6, where $\boldsymbol{U}_{C o n}$ represents voltage generated by LP Converter; $\boldsymbol{U}_{R e c}$ is voltage generated by Rectifier; $\boldsymbol{V}_{L 1}$ is the voltage across the inductor $L_{1}$ in Fig.3, and $\boldsymbol{I}_{R e c}$ is the current which flows from $L_{1}$ to Rectifier. The inductor $L_{1}$ shown in Fig. 3 is important due to two reasons: (1) separates $\boldsymbol{U}_{\text {Con }}$ and $\boldsymbol{U}_{R e c}$, and adjust $\boldsymbol{U}_{R e c}$ according to different load profiles; and (2) filter high frequency PWM harmonics. Therefore, the selection of $L_{1}$ should be discussed.

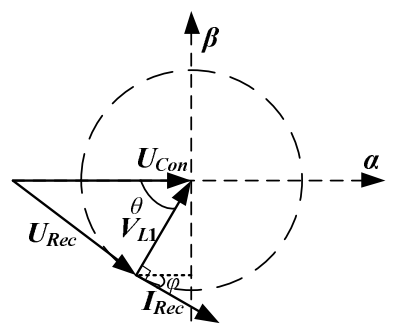

Fig.6 The relationship of voltage vectors at LP side.

According to cosine theorem, the following equation can be obtained:

$$
\begin{aligned}
\left|U_{\text {Rec }}\right|^{2} & =\left|U_{C o n}\right|^{2}+\left|V_{L 1}\right|^{2}-2\left|U_{C o n}\right|\left|V_{L 1}\right| \cos \theta \\
& =\left|U_{C o n}\right|^{2}+\omega^{2} L_{1}^{2}\left|I_{R e c}\right|^{2}-2 \omega L_{1}\left|U_{C o n}\right|\left|I_{R e c}\right| \sin \varphi
\end{aligned}
$$

Choose $L_{1}$ as the variable, then $L_{1}$ can be obtained as follows:

$$
\begin{aligned}
& L_{1}=\frac{\left|U_{C o n}\right| \sin \varphi+\sqrt{\left|U_{C o n}\right|^{2} \sin ^{2} \varphi+\left|U_{R e c}\right|^{2}-\left|U_{C o n}\right|^{2}}}{\omega\left|I_{R e c}\right|}
\end{aligned}
$$

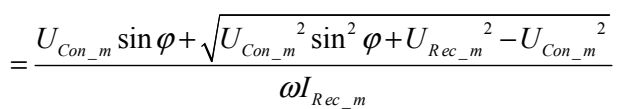

where $U_{\text {Con_m } m}, U_{R e c \_m}, I_{R e c \_m}$ represent the maximum value of $\boldsymbol{U}_{C o n}, \boldsymbol{U}_{R e c}$ and $\boldsymbol{I}_{R e c}$, respectively.

At full thrust $E_{0} \approx \omega_{e} \psi_{f}=45.8 \mathrm{~V}$. $U_{\text {Con } m}$ is similar to $E_{0}$ due to rather small stator inductance. The limitation of $I_{R e c}$ is set as 50A. Besides, since $i_{x L}$ and $i_{x R e c}(x=a, b, c)$ are controlled in phase as illustrated in next part, the power factor angle $\varphi$ will be as small as $20^{\circ}$. In this case, using (11), $L_{1} \leq 0.65 \mathrm{mH}$. In this paper, $L_{1}$ is chosen as $0.45 \mathrm{mH}$.

\section{Controller Design of Rectifier}

Since the phase terminals of LP generator and Rectifier branches share the same junctions as shown in Fig.3, an effective way to control the transferred power to Rectifier is to control the phase currents of LP generator $\left(i_{x L}\right)$ and Rectifier $\left(i_{x R e c}, x=a, b, c\right)$ in phase. Hence the ratio of phase current magnitude is proportional to the ratio of power.

Apart from regulating currents in phase, the Rectifier controller is also responsible to control the intermediate DC link voltage $V_{\text {mid }}$. However, if adopting the conventional cascaded structure with voltage outer loop and current inner loop, the output of voltage controller, which is the reference of active current, will not be able to control $i_{x R e c}$ and $i_{x L}$ in phase. To cope with this problem, a new method is proposed to fulfil both the DC voltage regulation and currents $i_{x R e c}$ and $i_{x L}$ in phase. The control diagram is shown in Fig.7. References of current loop come from the product of the actual LP generator $d q$ axes currents and gain $m$. Obviously, in this way the phase currents $i_{x R e c}$ and $i_{x L}$ can be controlled in phase if $i_{x R e c}$ and $i_{x L}$ conduct $a b c / d q$ transformation using same frame. And the value of $m$ comes from voltage loop. When $V_{\text {mid }}$ is smaller than its reference, $m$ should increase so that more current can be pumped into DC link and $V_{\text {mid }}$ will increase, and vice versa. Therefore, with such control method, $V_{\text {mid }}$ can be stabilized and $i_{x R e c}$ can be controlled in phase with $i_{x L}$. In other words, the two aims which are the stabilization of $V_{\text {mid }}$ and control of power transfer via $\mathrm{B} 2 \mathrm{~B}$ converter can be realized simultaneously.

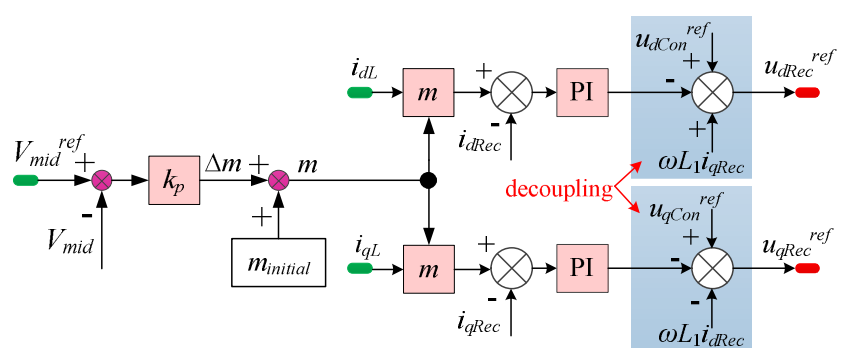

Fig.7 The control block diagram of Rectifier controller.

\section{Simulative VALIDATION}

In this section, simulations are conducted in Matlab/Simulink and MagNet. A real aircraft engine emulator 
system is constructed as shown in Fig.1. It is composed of one PMSM as HP SG, one switching reluctance machine as LP generator, and two induction machines (IMs) mimicking engine shaft behaviours and they are controlled by dSPACE. The speed range of the two induction machines is from 2000 to $20000 \mathrm{r} / \mathrm{min}$. The two IMs are controlled by two commercial two-level converter (Semikube). The PMSM is controlled by a three-level neutral-point-clamped (NPC) which can refer to [9]. Relevant experiments will be conducted in the future. Here simulation results will be given to verify the effectiveness of the proposed system.

\section{A. Proposed Power Generation Architecture in Dual- generator and Power-transfer modes}

In dual-generator mode, HP and LP machines both perform as generators. The results are shown from Fig.8(a) to (e). In power-transfer mode, HP machine performs as a motor to speed up HP shaft. The results are shown in Fig.8(f). In dual-generator mode, there are three different stages. Stage 1: $0 \mathrm{~s}$ to $0.1 \mathrm{~s}$, the power sharing ratio between LP and HP machines is $2: 1$. Total power demand is $10.6 \mathrm{~kW}$; Stage $2: 0.1 \mathrm{~s}$ to $0.2 \mathrm{~s}$, the power sharing ratio between LP and HP machines is changed to $3: 1$; Stage 3 : From $0.2 \mathrm{~s}$ to $0.3 \mathrm{~s}$, the total power demand increases to $17.5 \mathrm{~kW}$.

The $d q$ axes currents of LP and HP machines are shown in Fig.8(a) and (b). In Fig.8(b) $i_{d H P}$ is controlled to 0 due to the high DC voltage $V_{\text {mid }}$. This confirms that compared with former ideas [7], the proposed architecture allows the HP machine no longer to need to operate in the FW mode even at

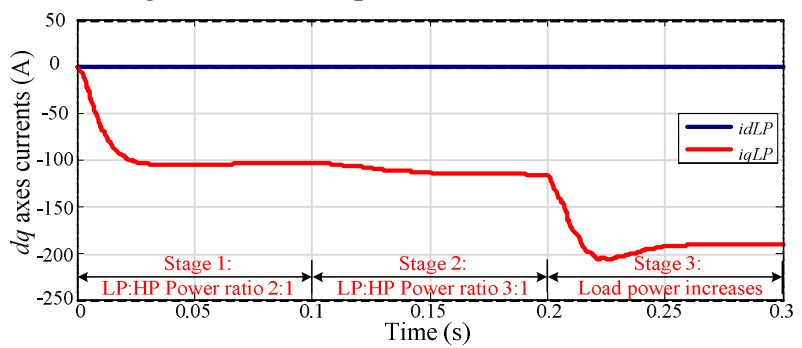

(a)

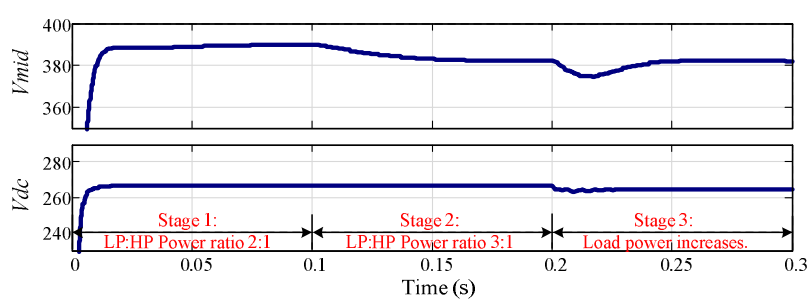

(c)
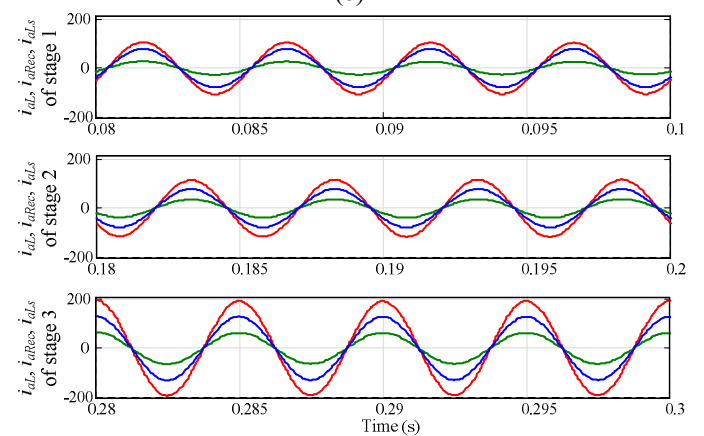

(e) high speed $20000 \mathrm{r} / \mathrm{min}$ This benefits to reduce the overall copper loss and hence improve efficiency.

The DC voltages of main bus $V_{d c}$ and intermediate stage $V_{\text {mid }}$ inside the B2B Converter are demonstrated in Fig.8(c). $V_{d c}$ remains stable during the whole process. This confirms the effectiveness of voltage controller and droop method in Section II A. As for $V_{\text {mid }}$, it also keeps stable during the whole process. And its value deviates from reference since only proportional effect is adopted to control $V_{\text {mid }}$ as shown in Fig.7. Since this intermediate DC voltage doesn't supply power to the on-board load directly, it doesn't matter if $V_{\text {mid }}$ slightly declines. And proportion control is useful enough as well as easy tuning. If the system requires a stable $V_{\text {mid }}$ the proportional controller can be replaced by a PI controller.

The output powers in dual-generator mode are exhibited in Fig.8(d). At stage 1 and 2, LP power is twice and triple of HP power, respectively. This confirms the effectiveness of proposed architecture to realize power sharing between sources by applying droop control.

The currents of $i_{a L}, i_{a R e c}$ and $i_{a L s}$ are shown in Fig.8(e). During the whole process, the $i_{a L}, i_{a R e c}$ and $i_{a L s}$ are tightly kept in phase, which confirms the effectiveness of Rectifier controller in Fig.7. And ratio of their current magnitudes is proportional to ratio of the powers at different stages.

The output powers in power-transfer mode are presented in Fig.8(f). HP machine performs as a motor which output $10 \mathrm{~kW}$ power to speed up the HP shaft. While LP machine on

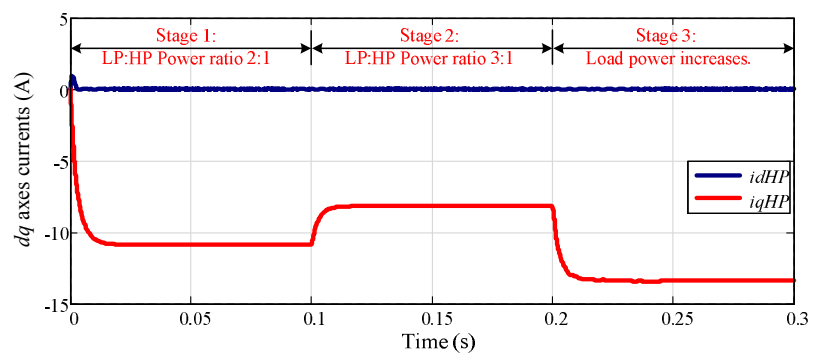

(b)

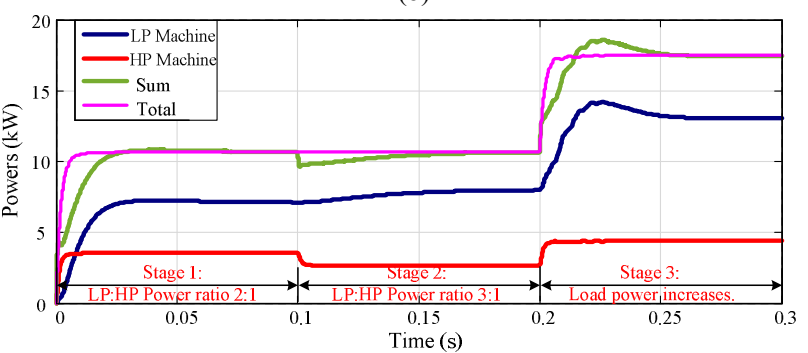

(d)

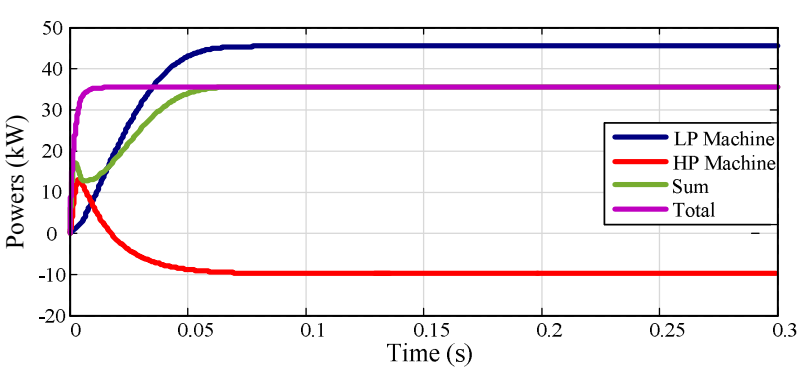

(f)

Fig.8. Results in dual-generator and power-transfer modes. (a) $d q$ currents of LP machine; (b) $d q$ currents of HP machine; (c) main DC voltage $V_{d c}$ and B2B DC voltage $V_{\text {mid }}$; (d) Powers in dual-generator mode; (e) LP machine phase current $i_{a L}$, Rectifier branch phase current $i_{a R e c}$ and LP side main branch phase current $i_{a L s}$. Red curve: $i_{a L}$; Blue: $i_{a L s}$; Green: $i_{a R e c}$. (Top to Bottom) currents of stage 1, 2, and 3, respectively. (f) Powers in power-transfer mode. 
the one hand supplies power to the loads attached on main DC bus, on the other hand supplies power to the HP machine. This confirms the feasibility of transferring power from LP to HP shaft using proposed architecture.

\section{B. Improvement of Engine Performance and Comparison of Power Losses of Different Architectures}

Maps from GASTURB is used to establish a two-spool high bypass ratio $(\mathrm{BPR}=8)$ unmixed flow $140 \mathrm{kN}$ turbofan by a mechanical expert in our group, where LPT drives fan and LPC via LP shaft, HPT drives axial HPC and radial HPC. Results of speeds, fuel consumption and compressor surge margin at flight idle mode are presented in Fig.9. It reflects that as the increase of transferred power from LP to HP shaft, LP speed will decline and that of HP shaft will rise, leading to the reduction of fuel consumption, and the enhancement of available compressors surge margins.

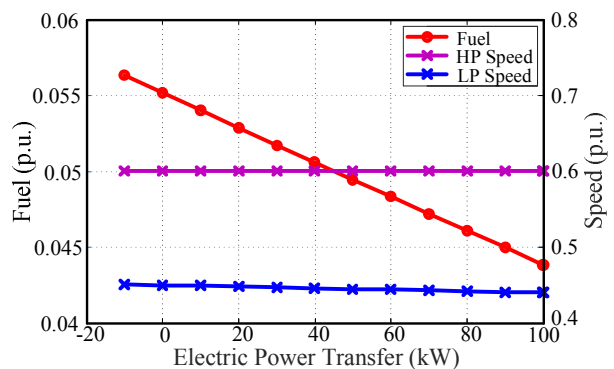

(a)

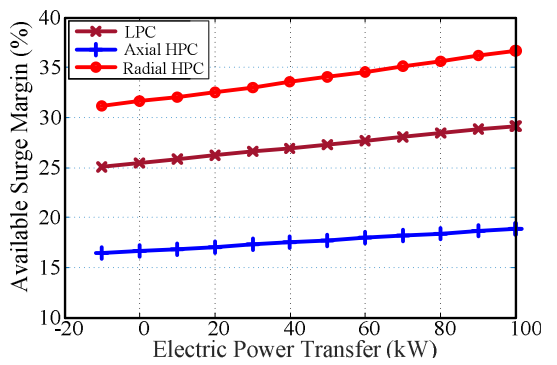

(b)

Fig.9. (a) Fuel consumption and shaft speeds at flight idle mode, 20000ft. (b) Surge margins of compressors at flight idle mode, $20000 \mathrm{ft}$.

The HP machine is built in the MagNet and its structure is shown in Fig.10. The details about the modelling and design of this machine can refer [10]-[11]. Two droop gains are set the same and power sharing ratio between LP and HP machines is set as 2:1. The power losses of HP machine obtained from the Finite Element Analysis tool MagNet are presented in Table I. Here the proposed architecture shown in Fig. 1 is denoted as $T_{1}$ and the architecture without B2B converter shown in [7] are denoted as $\mathrm{T}_{2}$.

From Table I it can be concluded that the machine total loss (including copper loss and iron loss) with $\mathrm{T}_{2}$ is smaller than that with $T_{1}$ since adopting $T_{2}$ could allow HP machine operates without flux weakening, leading to the small current when output the same active power, and therefore, the copper loss is reduced. Results in [10]-[11] have proved that for the high power-density PMM machine used in our system, copper loss accounts for the major part because this machine is specifically designed by choosing appropriate slot-pole combination and materials to reduce iron losses in high-speed region. Therefore, according to the results Table I, we can conclude that the overall power losses in the HP machine could be reduced by using the proposed power generation architecture.

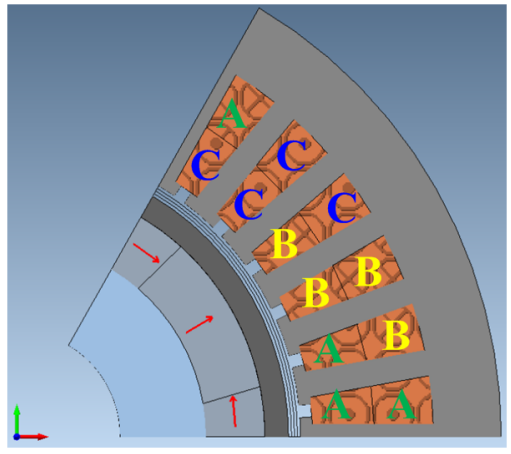

Fig.10. The structure of HP machine in the MagNet.

TABLE I. POWER LOSSES OF HP MACHINE WITH DIFFERENT ARCHITECTURES

\begin{tabular}{|c|c|c|}
\hline $\begin{array}{c}\text { Total Power } \\
(\mathrm{kW})\end{array}$ & $\begin{array}{c}d q \text { Currents }(\mathrm{A}) \text { and } \mathrm{HP} \\
\text { Machine Loss }(\mathrm{W}) \text { with } \mathrm{T}_{1}\end{array}$ & $\begin{array}{c}d q \text { Currents }(\mathrm{A}) \text { and HP } \\
\text { Machine Loss }(\mathrm{W}) \text { with } \mathrm{T}_{2}\end{array}$ \\
\hline 10 & $i q=-10.2, i d \approx 0$, & $i q=-10.2, i d=-115.7$, \\
& Total loss $=129.0$ & Total loss $=807.5$ \\
\hline 20 & $i q=-20.4, i d \approx 0$, & $i q=-20.4, i d=-116.4$, \\
& Total loss $=136.9$ & Total loss=830.5 \\
\hline 30 & $i q=-30.6, i d \approx 0$, & $i q=-30.6, i d=-117.4$, \\
& Total loss $=166.2$ & Total loss $=870.1$ \\
\hline 40 & $i q=-40.8, i d \approx 0$, & $i q=-40.8, i d=-118.8$, \\
& Total loss $=204.2$ & Total loss $=945.8$ \\
\hline
\end{tabular}

Besides the power loss of HP machine, the converter power losses is also considered and the results are presented in Fig.11. When adopting the topology $T_{1}$, large flux weakening current should be injected into HP machine even without outputting any active power due to its high speed. Obviously, this will lead to large converter power loss, including conduction loss and switching loss. If using the proposed topology $T_{2}$ as instead, the high-speed operation of HP machine doesn't need any flux weakening current since $V_{\text {mid }}$ is high enough. Then the magnitude of stator current will be smaller than that of $T_{1}$. However, more switching devices (IGBT) and diodes are involved in $\mathrm{T}_{2}$. Therefore, the converter losses of $T_{1}$ and $T_{2}$ need to be compared. For $T_{1}$, only HP Converter loss is studied; for $\mathrm{T}_{2}$, HP Converter, Rectifier and Inverter losses are studied. The conduction loss and switching loss are computed using the linear models in [12]-[13], and the output characteristic of devices are obtained from datasheet [14]. The operating points and power sharing ratios are configured the same as those of HP machine loss simulation.

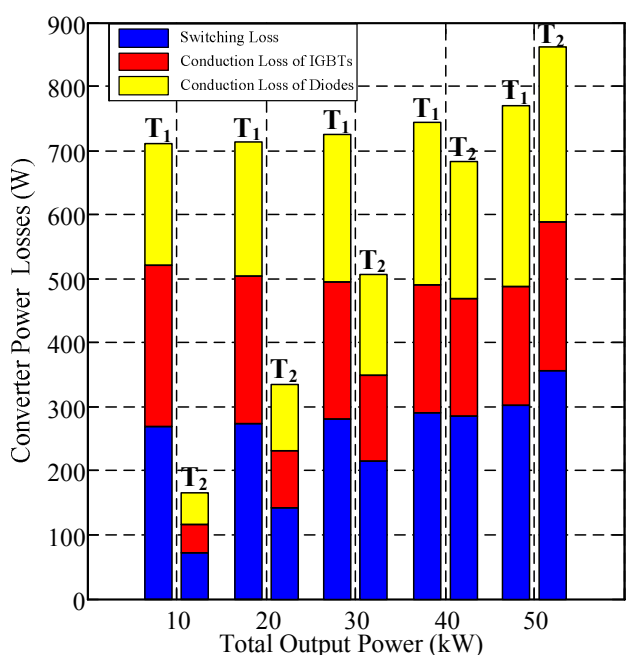

Fig.11 Converter Power losses comparison between $T_{1}$ and $T_{2}$. 
From Fig. 11 it can be seen that in light load condition, total power loss of $T_{1}$ is larger than that of $T_{2}$ due to large flux weakening current (negative $i_{d}$ ). While in heavy load condition, total power loss of $\mathrm{T}_{1}$ will be smaller than that of $\mathrm{T}_{2}$ since more semiconductor devices are involved in $T_{2}$. However, if we choose wide band gap (WBP) devices to construct the $\mathrm{B} 2 \mathrm{~B}$ converter, like $\mathrm{SiC}$, we can expect that the power losses on the B2B converter can be largely reduced even in the heavy load conditions. The research regarding this issue will be conducted in the future study.

\section{CONCLUSION}

A dual-channel power generation architecture containing a back-to-back converter in MEA application is proposed in this paper. Modeling and control method design are elaborated. Relevant simulative results are given, confirming that the proposed idea can realize the following functions.

Firstly, the proposed architecture can allow the system to operate in both dual-generator mode and power transfer mode. In dual-generator mode, the two channels can both supply power to the loads on main DC bus by a specific power sharing ratio. In power-transfer mode, some power can be transferred from LP to HP spool at flight idle mode to enhance the engine performance. It reduces fuel consumption and enlarge compressor surge margin.

Secondly, by including the back-to-back converter, a high-voltage intermediate DC bus can be established. It allows the HP machine to operate at a high speed $(20 \mathrm{k} \mathrm{r} / \mathrm{min})$ without flux weakening. Therefore the root-mean-square (RMS) current is largely reduced, which benefits to decrease the overall power loss.

\section{ACKNOWLEDGMENT}

This project has received funding from the Clean Sky 2 Joint Undertaking under the European Union's Horizon 2020 research and innovation program under grant agreement No 807081. The author Xiaoyu Lang also thanks the stipend funding from China Scholarship Council (CSC).

\section{REFERENCES}

[1] B. Sarlioglu and C. T. Morris, "More electric aircraft: Review, challenges, and opportunities for commercial transport aircraft," IEEE Trans. Transport. Electrific., vol. 1, no. 1, pp. 54-64, Jun. 2015.

[2] H. B. Enalou, M. Rashed, and et al, "Nonlinear aircraft engine model for future integrated power center development," 2016 International
Conference on Electrical Systems for Aircraft, Railway, Ship Propulsion and Road Vehicles \& International Transportation Electrification Conference (ESARS-ITEC), Toulouse, 2016, pp. 1-5.

[3] H. B. Enalou, M. Rashed, P. Kulsangcharoen, S. Chowdhury and S. Bozhko, "A Twin Spool Engine Emulator for the Study of Power Exchange Idea," 2018 IEEE International Conference on Electrical Systems for Aircraft, Railway, Ship Propulsion and Road Vehicles \& International Transportation Electrification Conference (ESARSITEC), Nottingham, 2018, pp. 1-8.

[4] K. Muehlbauer and D. Gerling, "Two-generator-concepts for electric power generation in more electric aircraft engine," in Proc. Int Conf. Elect. Mach., 2010, pp.1-5.

[5] Y. Jia and K. Rajashekara, "An Induction Generator-Based AC/DC Hybrid Electric Power Generation System for More Electric Aircraft," IEEE Trans. Indus. Appl., vol. 53, no. 3, pp. 2485-2494, June 2017.

[6] R. Todd, et al, "Effects of electrical power off-take on finite inertia mechanical systems," in Proc. IEEE Energy Convers. Congr. Expo., 2011, pp. 1476-1482.

[7] X. Lang, T. Yang, H. B. Enalou, S. Bozhko and P. Wheeler, "An Enhanced Power Generation Centre for More Electric Aircraft Applications," 2018 IEEE International Conference on Electrical Systems for Aircraft, Railway, Ship Propulsion and Road Vehicles \& International Transportation Electrification Conference (ESARSITEC), Nottingham, 2018, pp. 1-6.

[8] F. Gao, S. Bozhko, G. Asher, P. Wheeler, and C. Patel, "An improvedvoltage compensation approach in a droop-controlled DC power system for the more electric aircraft," IEEE Trans. Power Electron., vol. 31, no. 10, pp. 7369-7383, Oct. 2016.

[9] C. Li, T. Yang, P. Kulsangcharoen, G. L. Calzo, S. Bozhko, C. Gerada, and P. Wheeler, "A modified neutral-point balancing space vector modulation technique for three-level neutral point clamped converters in high speed drives," IEEE Trans. Ind. Electron., vol. 66, no. 2, pp. 910-921, Feb. 2019

[10] W. U. N. Fernando, P. Arumugam, and C. Gerada, "Design of a stator for a high-speed turbo-generator with fixed permanent magnet rotor radius and volt-ampere constraints," IEEE Trans. Energy Conver., vol. 33, no. 3, pp. 1311-1320, 2018.

[11] W. Fernando, P. Arumugam and C. Gerada, "Volt-ampere constrains and its influence on inductance limits in high speed PM machine design," 8th IET International Conference on Power Electronics, Machines and Drives (PEMD 2016), Glasgow, 2016, pp. 1-6.

[12] Z. Xu, D. Zhang, F. Wang and D. Boroyevich, "A Unified Control for the Combined Permanent Magnet Generator and Active Rectifier System," IEEE Trans. Power Electron., vol. 29, no. 10, pp. 5644-5656, Oct. 2014.

[13] I. Statudt, 3L NPC \& TNPC Topology, Semikron Application Note: An-11001, SEMIKRON.

[14] SEMIKRON DataSheet SKiM459GD12E4_23930010.

[15] Q. Ni, M. Yang, S. Odhano, M. Tang and et al., " A New Position and Speed Estimation Scheme for Position Control of PMSM Drives Using Low-resolution Position Sensors," IEEE Trans. Ind. Appl., pp. 1-1, Mar. 2019. 